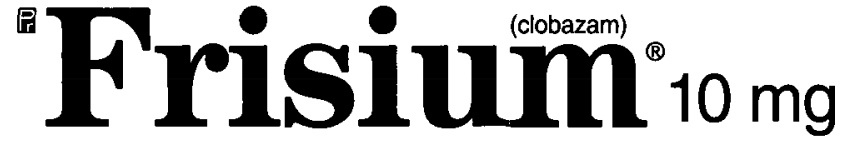

FOR A COMPREHENSIVE APPROACH TO SEIZURE CONTROL

Frisium (clobazam) Tablets $10 \mathrm{mg}$

THERAPEUTIC CLASSIFICATION Anticonvu'sant for adjunctive therapy. INDICATIONS Frisium (clobazam) has been found to be of value as adjunctive therapy in patients with epilepsy who are not adequately stabilized with their current anti-convulsant therapy. CONTRAINDICATIONS Hypersensitivity to clobazam, severe muscle weakness (myasthenia gravis) and narrow angle glaucoma. WARNINGS Use in the elderly: Frisium (clobazam) should be used with caution in elderly and debilitated patients, and those with organic brain disorders, with treatment initiated at the lowest possible dose. [See Precautions]. Potentiation of drug affecls: Patients should be cautioned about the possibility of additive effects when Frisium is combined with alcohol or other drugs with central nervous system depressant effects. Patients should be advised against consumption of alcohol during treatment with Frisium. [See Precautions]. Physlcal and psychological dependence: Physical and psychological dependence are known to occur in persons taking benzodiazepines. Caution must be exercised if it is at all necessary to administer Frisium to individuals with a history of drug misuse or those who may increase the dose on their own initiative. Such patients must be placed under careful surveillance. Signs and symptoms of withdrawal may follow discontinuation of use of Frisium; thus it should not be abruptly discontinued after prolonged use. [See Precautions]. Use in pregnancy: Frisium should not be used in the first trimester of pregnancy and thereatter only if strictly indicated. Nursing mothers in whom therapy with Frisium is indicated should cease breast-feeding since clobazam passes into breast milk. Several studies have suggested an increased risk of congenital malformations associated with the use of minor tranquilizers (chlordiazepoxide, diazepam and meprobamate) during the first trimester of pregnancy. If Frisium is prescribed to a woman of child-bearing potential she should be warned to consult her physician regarding the discontinuation of the drug if she intends to become, or suspects she might be, pregnant. Anterograde amnesia: Anterograde amnesia is known to occur after administration of benzodiazepines. Use In patlents with depression or psychosls: Frisium is not recommended for use in patients with depressive disorders or psychosis. PRECAUTIONS Driving and Hazardous Activities: Frisium (clobazam) possesses a mild centra nervous system depressant effect, therefore patients should be cautioned against driving, operating dangerous machinery or engaging in other hazardous activities, particularly in the dose adjustment period, or until it has been established that they do not become drowsy or dizzy. Use in the Elderty: Elderly and debilitated patients, or those with organic brain syndrome, have been found to be prone to the CNS depressant activity of benzodiazepines even after low doses. Manifestations of this CNS depressant activity include ataxia, oversedation and hypotension. Therefore, medication should be administered with caution to these patients, particularly if a drop in blood pressure might lead to cardiac complications. Initial doses shoutd be low and increments should be made gradually, depending on the response of the patient, in order to avoid oversedation, neurological impairment and other possible adverse reactions. Dependence Liability: Frisium should not be administered to individuals prone to drug abuse. Caution should be observed in all patients who are considered to have potential for psychological dependence. Withdrawal symptoms have been observed after abrupt discontinuation of benzodiazepines. These include irritability, nervousness, insomnia, agitation, tremors, convulsions, diarrhea, abdominal cramps, vomiting and mental impairment. As with other benzodiazepines, Frisium should be withdrawn gradually. Tolerance: Loss of part or all of the anti-convulsant effectiveness of clobazam has been described in patients who have been receiving the drug for some time. There is no absolute or universal definition for the phenomenon and reports vary widely on its development. The reported success of clobazam in intermittent therapy in catamenia epilepsy implies that tolerance may be minimized by intermittent treatment but long-term follow-up is unreported. No studies have identified or predicted which patients are likely to develop tolerance or precisely when this might occur. Use in Mental and Emotional Disorders: It should be recognized that suicidal tendencies may be present in patients with emotional disorders; particularly those depressed. Protective measures and appropriate treatment may be necessary and should be instituted without delay. Since excitement and other paradoxical reactions can result from the use of benzodiazepines in psychotic patients, Clobazam should not be used in patients suspected of having psychotic tendencies. Use In Patients with Impaired Renal or Hepatic Functlon: Clobazam requires dealkylation and hyoroxylation before conjugation. Usual precautions should be taken if Frisium is used in patients who may have some impairment of renal or hepatic function. It is suggested that the dose impairment of renal or hepatic function. It is suggested that the dose
in such cases be carefully titrated. In patients for whom prolonged therapy with Frisium is indicated, blood counts and liver function should be monitored periodically. Use in Patients with Acute, Severe Respiratory Insufficiency: In patients with acute, severe respiratory insufficiency, respiratony function should be monitored laboratory Tests: If Frisium is administered for repeated cycles of therapy, periodic blood counts and liver and thyroid function tests are advisable. Drug Interactions: Most studies of the potential interactions of clobazam with other anti-epileptic agents have failed to demonstrate significant interactions with phenytoin, phenobarbital, or carbamazepine. However, one study noted that the addition of clobazam caused a $25 \%$ increase in serum drug levels in $29 \%$ of patients taking carbamazepine, $63 \%$ of patients taking phenytoin $13 \%$ of those taking valproate and $14 \%$ of those on phenobarbital. The contradictory findings in different studies are presumably due to variations in patient susceptibility, and although clinically significan significantly increase plasma clobazam levels. Several of the established anti-epileptic agents: carbamazepine diphenylhydantoin, phenobarbital, valproic acid, cause the blood levels of clobazam to decrease slightly. Findings are less consistent with regard to $\mathrm{N}$-desmethylclobazam: serum levels are lower with concurrent valproic acid, but higher with carbamazepine and associated with hepatomas in high-dose males. In rat an increased

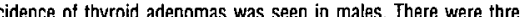
malignancies: two (male and fernale) in the thyroid and one (female) in the liver. The relevance of these findings to man has not been established. ADVERSE REACTIONS From 19 published studies of Frisium (clobazam) use in epileptic patients, the overall incidence of side-effects was $33 \%$ of which drowsiness, dizziness and fatigue were most frequently reported. Canadian experience provides a (32\%) with drowsiness reported in $17.3 \%$ of patients, and $12 \%$ of patients terminating treatment because of sideeffects. The incidence of side-effects was lower in patients under whereas treatment discontinuation incidences were similar across age groups: $10.6 \%$ and $13.8 \%$ respectively. The following side-effects occurred at incidences of oreater than $1 \%$ (ataxia $[3.9 \%]$ weight gain [2.2\%], dizines [1.8\%], nerrousness [1.6\%], behaviour disorde $[1.4 \%]$, hostility and blurred vision [1.3\%]) while other effects $[1.4 \%]$, hostility and blurred vision [1.3\%]) while other effects
occurred at a less than $1 \%$ incidence. Symptoms of tiredness may sometimes appear, especially at the beginning of treatment with Frisium and when higher doses are used. Also in rare instances and usually only temporarily, the patient may experience dryness of the mouth, constipation, loss of appetite, nausea, dizziness, muscle weakn, constipalion, loss or appetie, nausea, dizzis but also paradoxical reactions, e g. restlessness and irritability. After prolonged use of benzodiazepines, impairment of consciousness combined with respiratory disorders has been reported in very rare cases, particularly in elderly patients; it sometimes persisted for some length of time. Under experimental conditions, impairment of alertness has been observed to be less pronounced after therapeutic doses of clobazam than after other benzodiazepines. Nevertheless, even when used as directed, the drug may alter reactivity to such an extent as to impair driving performance or the ability to operate machinery, especially when it is taken in conjunction with alcohol. As with other drugs of this type (benzodiazepines), the therapeutic benefit must be balanced against the risk of habituation and dependence during prolonged use. Isolated cases of skin reactions such as rashes or urticaria have been observed. DOSAGE AND ADM INISTRATION As with other benzodiazepines, the possibility of a ADMcrearin in anticonvulsant efficacy in the course of treatment must be borne in mind. In patients with impaired liver and kidney function, Frisium (clobazam) should be used in reduced dosage. Adults: Smal doses, 5-15 mg/day, should be used initially, gradually increasing to a maximum daily dose of $80 \mathrm{mg}$ as necessary. Children: In infants ( $<2$ years), the initial daily dose is $0.5-1 \mathrm{mg} / \mathrm{kg} / \mathrm{day}$. The initial dose in children (2-16 years) should be $5 \mathrm{mg} /$ day, which may be increased at 5 -day intervals to a maximum of $40 \mathrm{mg} /$ day. As with all benzodiazepines, abrupt withdrawal may precipitate seizures. It is therefore recommended that Frisium be gradually reduced in dose before treatment is discontinued. Administration: If the daily dose is divided, the higher portion should be taken at night. Daily doses up to $30 \mathrm{mg}$ may be taken as a single dose at night. AVAILABiLITY Frisium is available as white, uncoated, bevelled, round tablets of $7 \mathrm{~mm}$ diameter, marked with 'BGL' above and below the scorebreak on the obverse and the Hoechst 'Tower and Bridge' logo on the reverse. Frisium $10 \mathrm{mg}$ tablets are packaged in blisters of PVC film and aluminium foil and are distributed in packs of 30 [3×10] tablets. Product Monograph available on request. interactions are unusual, they may occur. Alcohol may also diphenylhydantoin. Toxicologlc Studies: In mouse, clobazam was 16 years of age $(23.7 \%)$ than the incidence in adults $(43.1 \%)$ : $p<0.05$

References: 1 Schmidt D. Clobazam for treatment of intractable epilepsy: A critical assessment. Epilepsia 1994;35(Suppl.5):S92-S95 2 Canadian Clobazam Cooperative Group. Clobazam in the treatment of refractory epilepsy: The Canadian Experience. A retrospectiv study. In: Epilepsia 1991, 32(3): 407-416.

Hoechst Marion Roussel

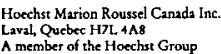

Hoechst $B$
KING MEDICAL

THE CANADIAN ELECTRODE PLACE
- CHALGREN
- DANTEC
- KENDALL-LTP
- KING MEDICAL
- MEDICOTEST
- PARKER LAB.
- D.O. WEAVER

Biggest selection in Canada of disposable Electrodes

Tel (905) 833-3545

Fax (905) 833-3543

E-mail king@lerdorf.on.ca

King Medical Ltd.

145 Kingsworth Road

King City • Ontario L7B $1 \mathrm{~K} 1$

\section{ADVERTISERS INDEX}

Abbott

Epival - ifc, xxix, xxx

Berlex

Betaseron - vi, vii, xxxix, xl

Glaxo Wellcome

Imitrex - xiv, xv, xxxv

Lamictal - iv, v, xvi, xvii, xxxvii, xxxviii

Hoechst Marion Roussel

Frisium - ibc, xxviii, xli

Sabril - iii, $x, x i$

Janssen - Ortho

Topomax - viii, ix, xx, xxi, xxxiii, xxxiv, $x x x v$

Novartis Pharma Canada Inc.

Migranal - xviii, xix, xxi, obc, xxxii

Tegretol - xxiv, xxxi, xxxii

Parke Davis

Neurontin - xiii, xxii, xxiii, xxxvi

Classified Ads

- xli, xlii, xliii

Draxis Health

Permax - xxvii, xlii 